\title{
NILAI EKONOMI PENDAYAGUNAAN KONSUMTIF HIJAUAN MAKANAN TERNAK YANG DIMANFAATKAN OLEH MASYARAKAT DARI KAWASAN HUTAN
}

\author{
The Economy Value of Cattle Food Greenery Utilization Used by People in \\ Forest Areas
}

Fahriza Luth, Raizal Fahmi Solihat, Syarif Hidayat

Fakultas Kehutanan Universitas Winaya Mukti;

Jl. Raya Bandung-Sumedang km 29 Tanjungsari, Sumedang 45362

Diterima 6 April 2020/Disetujui 13 April 2020

\begin{abstract}
Cattle food greenery is an important factor in supporting ruminant farming to improve optimally with good result besides breeding factor and procedures. Ruminant farming needs greenery feeding at least $10 \%$ of its weight to fill up its energy needs. A good quality feeding must be provided continually to support the ruminant farming. People in villages use farming areas, plantations, and vacant areas along the streets as plant production area for their livestock, and people living near the forests use forest area as greenery source for their cattle. However, people recently have little awareness to preserve the forest due to their lack of knowledge to value the advantages of the forest they benefit from every day. This circumstances frequently lead to pressure towards the forest. This research is aimed to find out the amount of cattle food greenery in every family unit monthly, to know the economy value of cattle food greenery which is earned by the people from the forest area, and to inform people to raise their knowledge and awareness towards the importance of forest use and its preservation. This research used survey method to obtain data in current condition by involving 140 respondents. The result shows that there are 8.650 sacks (50 $\mathrm{kg}$ each) of cattle food greenery which are earned by each family unit from the forest, with 62 sacks approximately. The total economy value of cattle food greenery is $R p$. 126.600.000 monthly with the average number as much as Rp. 904.285,71 per family unit.
\end{abstract}

Keywords: Economy value, cattle food greenery, forest area 


\section{PENDAHULUAN}

Hijauan Makanan Ternak (HMT) merupakan salah satu faktor yang sangat penting untuk mendukung perkembangan budidaya ternak ruminansia agar mampu tumbuh secara optimal dengan hasil yang memuaskan, selain faktor bibit dan tatalaksana. Ternak ruminansia membutuhkan hijauan pakan paling tidak sebanyak $10 \%$ dari berat tubuhnya untuk memenuhi kebutuhan energinya (Prabowo, 2010). Pakan ternak yang berkualitas harus tersedia secara berkelanjutan agar dapat menunjang budidaya ternak ruminansia.

Faktor penting yang harus diperhatikan dalam peningkatan produktivitas ternak adalah ketersediaan pakan yang mencukupi secara kualitas dan kuantitas. Masyarakat di pedesaan biasanya memanfaatkan areal persawahan, perkebunan, pinggir-pinggir jalan dan kawasan hutan sebagai sumber penghasil hijauan. Menurut Hanafi, (2008), hijauan pakan ternak yang paling umum digunakan oleh petani ternak meliputi daun-daunan dari tanaman rumput-rumputan (Gramineae), tanaman biji-bijian, dan kacang-kacangan (leguminosae). Tanaman penghasil hijauan pakan ternak sudah seharusnya tetap terjaga ketersediaanya agar menjamin keberlangsungan budidaya ternak ruminansia di pedesaan. Sitindaon (2013) mengatakan bahwa masalah utama dalam produktivitas ternak adalah sulitnya menyediakan pakan secara berkesinambungan baik jumlah maupun kualitasnya.. Ketersediaan lahan sumber hijauan pakan ternak sangat mempengaruhi ketersediaan hijauan makanan ternak yang dibutuhkan masyarakat. Hal tersebut mengisyaratkan bahwa lahan merupakan salah satu komponen penting dalam teknologi bioindustri selain peternak, ternak, dan peternakan. Salah satu solusi yang kerap dilakukan oleh masyarakat desa guna memenuhi kebutuhan hijauan makanan ternak adalah dengan memanfaatkan kawasan hutan menjadi sumber hijauan makanan ternak, khususnya masyarakat desa yang berbatasan dengan kawasan hutan. Wilayah hutan memiliki aneka vegetasi yang beragam meliputi pohon, semak, herba, dan rumput. Rumput alam yang tumbuh di hutan memiliki spesies yang dominan dibanding dengan semak dan herba (Nahdi dan Darsikin, 2013)

Dusun Ciburuan dan dusun Cicae merupakan dusun di desa Jingkang kecamatan Tanjungmedar kabupaten Sumedang yang berbatasan dengan kawasan hutan, tepatnya kawasan hutan RPH Ciburuan BKPH Buah Dua KPH Sumedang Perum Perhutani Divisi Regional Jawa Barat dan Banten. Sebagian besar masyarakat dusun Ciburuan dan Cicae adalah petani, baik pertanian lahan kering maupun lahan basah. Selain itu, masyarakat dusun Ciburuan dan Cicae juga 
melakukan budidaya ternak ruminansia seperti kambing, domba dan sapi guna menambah penghasilan keluarga. Dalam menunjang aktivitas perekonomian, masyarakat dusun Ciburuan dan Cicae berinteraksi dengan kawasan hutan guna memanfaatkan sumberdaya hutan, diantaranya adalah hijauan makanan ternak untuk memenuhi kebutuhan makanan ternak ruminansia yang mereka miliki. Hal tersebut terjadi karena hutan dianggap sebagai sumber hijauan makanan ternak yang dapat menjamin ketersediaan dalam jumlah yang dibutuhkan.

Meskipun masyarakat yang hidup di sekitar kawasan hutan sangat bergantung pada sumber daya hutan dalam memenuhi kebutuhan hidup, namun hingga saat ini kesadaran masyarakat untuk melestarikan hutan masih tergolong rendah. Hal tersebut disebabkan kurangnya pengetahuan masyarakat dalam menilai manfaat sumberdaya hutan yang telah mereka pergunakan setiap hari. Terkadang tekanan terhadap kawasan hutan masih sering terjadi akibat aktivitas masyarakat yang tidak memperhatikan aspek kelestarian.

Pengelolaan hutan yang baik harus dilakukan dengan upaya peningkatan kapasitas dan pengetahuan kepada masyarakat sehingga kesadaran masyarakat berkenaan dengan pentingnya hutan bagi kehidupan dapat terbangun. Hal tersebut harus dilakukan dengan mentransformasi pengetahuan dan informasi melalui saluran yang tepat dan metode yang sesuai. Untuk itu, informasi mengenai nilainilai sumberdaya hutan yang dimanfaatkan oleh masyarakat harus terus digali dan dikembangkan untuk upaya penyadartahuan masyarakat bahwa ternyata hutan telah memberikan kontribusi besar dan nyata dalam kehidupan sehari-hari, diantaranya adalah hijauan makanan ternak.

Penelitian ini bertujuan untuk mengetahui jumlah penggunaan hijauan makanan ternak per bulan untuk setiap kepala keluarga dan nilai ekonomi hijauan makanan ternak yang dimanfaatkan masyarakat dari kawasan hutan. Hasil penelitian ini diharapkan dapat bermanfaat sebagai informasi untuk meningkatkan pegetahuan dan kesadaran masyarakat terhadap pentingnya hutan dalam upaya pengelolaan hutan lestari.

\section{METODE PENELITIAN}

Penelitian dilaksanakan di desa Jingkang kecamatan Tanjungmedar kabupaten Sumedang (Gambar 1) selama satu bulan yaitu pada bulan Februari 2020. Alat yang digunakan yaitu alat tulis, kamera, GPS, kuesioner, alat perekam suara dan kalkulator. Sedangkan obyek penelitian adalah masyarakat dusun 
Ciburuan dan dusun Cicae desa Jingkang yang memiliki ternak ruminansia dan melakukan pemungutan hijauan makanan ternak dari dalam kawasan hutan.

Penelitian dilakukan menggunakan metode survey untuk memperoleh data pada kondisi yang sedang terjadi (existing), dengan pengumpulan data melalui dua tahap, yaitu : 1) Survey pendahuluan, dilakukan untuk mendapatkan informasi mengenai kondisi masyarakat desa sekitar hutan, pola pemanfaatan hijauan makanan ternak di kawasan hutan dan jumlah kepala keluarga yang beternak ruminansia di dusun Ciburuan desa Jingkang. Data ini digunakan untuk menentukan responden; 2) Observasi dan Wawancara, dilakukan menggunakan kuesioner untuk mengetahui pola pemungutan dan jumlah penggunaan hijauan makanan ternak setiap hari oleh masyarakat.

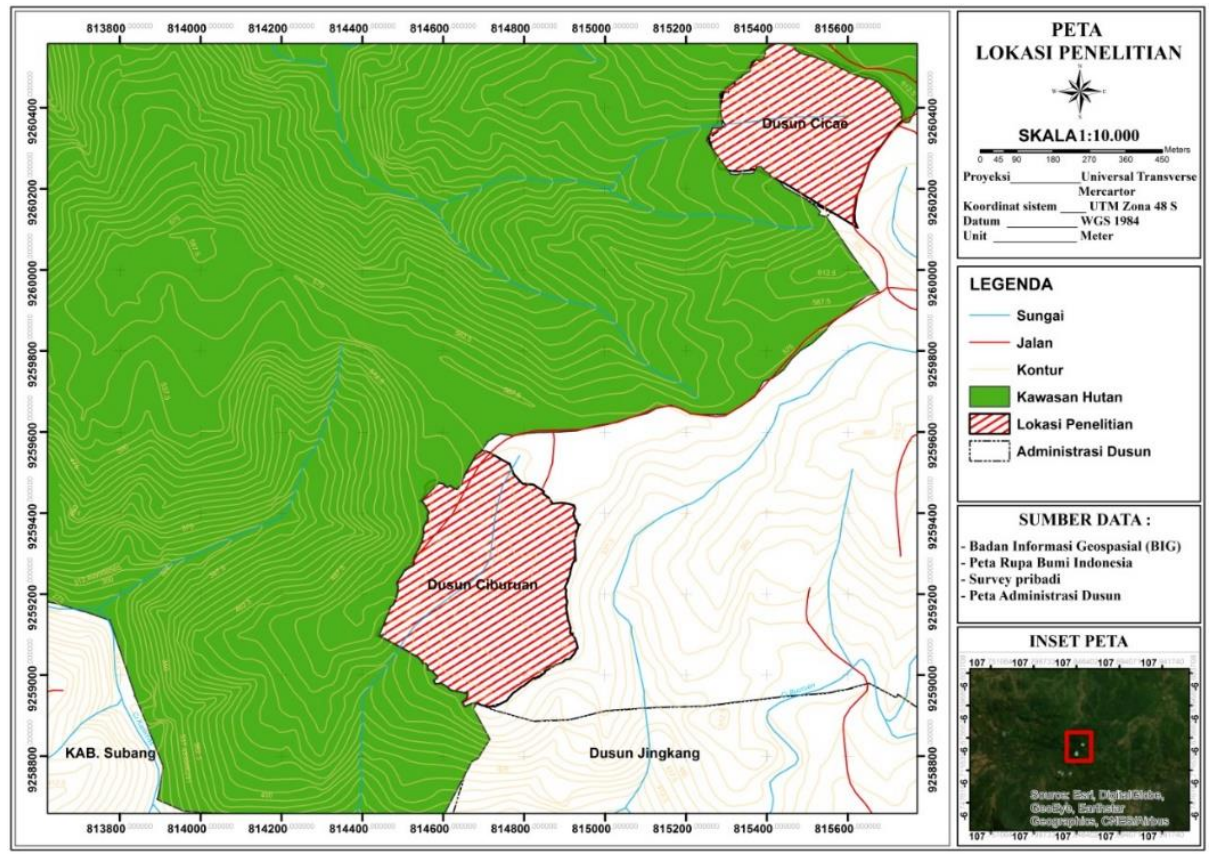

Gambar 1. Lokasi penelitian

Penentuan responden dalam penelitian ini dilakukan secara acak dari populasi kepala keluarga yang memiliki ternak ruminansia dan dalam sehariharinya memanfaatkan kawasan hutan untuk memenuhi kebutuhan hijauan makanan ternaknya.

Berdasarkan survey pendahuluan yang dilakukan di dusun Ciburuan dan dusun Cicae desa Jingkang diperoleh data jumlah keluarga yang memiliki ternak ruminansia dan memanfaatkan kawasan hutan untuk memungut hijauan makanan ternak yaitu sebanyak 51 kepala keluarga pada dusun Ciburuan dan sebanyak 89 
kepala keluarga pada dusun Cicae sehingga jumlah responden dalam penelitian sebanyak 140 orang .

Penentuan nilai ekonomi hasil hutan berupa hijauan makanan ternak yang dimanfaatkan oleh rumah tangga dihitung dengan pendekatan metode nilai pasar, menggunakan perkalian antara jumlah volume hasil hutan yang diambil dengan rata-rata harga pasar barang tersebut. Berdasarkan informasi yang diperoleh dari masyarakat pada saat survey pendahuluan, harga pasar hijauan makanan ternak yang berlaku di desa Jingkang adalah Rp. 15.000,- per karung $50 \mathrm{~kg}$. Pengolahan data dilakukan dengan tabulasi menggunakan software Microsoft Excel.

\section{HASIL DAN PEMBAHASAN}

Beternak ruminansia merupakan salah satu pilihan bagi masyarakat sekitar hutan sebagai upaya untuk meningkatkan penghasilan keluarga dengan memanfaatkan kawasan hutan sebagai sumber pakannya. Ginting (2012) mengatakan bahwa petani harus mencari alternatif lain sebagai upaya meningkatkan pendapatan mereka, karena tingkat pendapatan yang didapatkan dari sektor pertanian tanaman pangan tidaklah mencukupi untuk memenuhi kebutuhan hidup keluarga petani. Salah satu usaha manusia dalam memanfaatkan lingkungan fisik adalah usaha peternakan. Hal tersebut sesuai dengan pernyataan Umi (2010) yang menyatakan bahwa usaha peternakan sapi potong hanya merupakan pekerjaan sampingan, sedang pekerjaan utamanya adalah petani.

Hijauan makanan ternak merupakan salah satu sumberdaya hutan yang banyak dimanfaakan oleh masyarakat Desa Jingkang khususnya dusun Ciburuan dan dusun Cicae, selain jenis-jenis sumberdaya hutan lainnya yang terkandung dalam kawasan hutan RPH Ciburuan BKPH Buahdua. Hijauan makanan ternak tersebut digunakan sebagai pakan ternak ruminansia yang dimiliki oleh masyarakat sebagai salah satu usaha sampingan masyarakat selain bertani. Jenis tumbuhan hijauan yang sering dimanfaatkan masyarakat dari kawasan hutan dapat dilihat pada Tabel 2.

Tabel 2 Jenis tumbuhan HMT yang dimanfaatkan dari kawasan hutan

\begin{tabular}{|c|c|c|}
\hline \multirow{2}{*}{ No } & \multicolumn{2}{|c|}{ Jenis HMT } \\
\hline & Lokal & Latin \\
\hline 1 & Gadung & Dioscorea hispida \\
\hline 2 & Jarong & Achyranthes aspera \\
\hline 3 & Kahitutan & Paederia foetida \\
\hline 4 & Teklan & Eupatorium riparium \\
\hline 5 & Alang-alang & Imperata cylindrical \\
\hline
\end{tabular}




\begin{tabular}{cll}
\hline \multirow{2}{*}{ No } & \multicolumn{2}{c}{ Lenis HMT } \\
\cline { 2 - 3 } & \multicolumn{1}{c}{ Lokal } & \multicolumn{1}{c}{ Latin } \\
\hline 6 & Jampang pait & Digitaria radicosa \\
7 & Cacabean & Ludwigia octovalvis \\
8 & Kaliandra & Calliandra sp. \\
9 & Rumput-rumputan & Gramineae \\
\hline & & Sumber : Data primer
\end{tabular}

Tabel 2 menunjukkan bahwa jenis tumbuhan yang sering dimanfaatkan oleh masyarakat dari kawasan hutan terdiri dari 9 jenis yaitu Gadung, Jarong, Kahitutan, Teklan, Alang-alang, Jampang pait, Cacabean, Kaliandra dan jenis Rumput-rumputan.

Adapun volume penggunaan hijauan makanan ternak dari kawasan hutan oleh masyarakat desa Jingkang dan nilai ekonominya yaitu :

1. Volume HMT yang Dimanfaatkan oleh Masyarakat

a. Volume HMT Satu Kali Pengambilan

Jumlah hijauan makanan ternak yang di ambil oleh 140 responden yaitu sebanyak 295,5 karung dalam satu kali pengambilan dengan rata-rata pengambilan 2,11 karung per kepala keluarga. Jumlah pengambilan hijauan makanan ternak oleh masyarakat tersebut terdiri dari jumlah pengambilan dari dua dusun di desa Jingkang yang diteliti, yaitu sebanyaak 93 karung oleh masyarakat dusun Ciburuan dan 202,5 karung oleh masyarakat dusun Cicae.

\section{b. Jumlah Pengambilan HMT dalam Satu Bulan}

Jumlah pengambilan hijauan makanan ternak dalam satu bulan oleh 140 responden adalah sebanyak 4.075 kali dengan rata-rata 29 kali pengambilan dalam satu bulan per kepala keluarga. Hal ini disebabkan karena ada responden yang mengambil hijauan makanan ternak dengan frekuensi 15 dan 20 kali per bulan dengan alasan jumlah hewan ternak yang dimiliki hanya sedikit sehingga satu kali pengambilan dapat digunakan untuk $2-3$ hari.

\section{c. Volume HMT Satu Bulan Pengambilan}

Volume hijauan makanan ternak yang diambil dari kawasan hutan dalam satu bulan oleh 140 responden adalah sebanyak 8.650 karung dengan rata - rata 62 karung setiap kepala keluarga. Volume hijauan makanan ternak tersebut merupakan penjumlahan volume HMT yang diambil dari dua dusun di desa Jingkang yang diteliti, yaitu sebanyak 2.770 karung oleh masyarakat dusun Ciburuan dan 5.880 karung oleh masyarakat dusun Cicae. 
Berdasarkan penghitungan hasil penelitian tersebut dapat dilihat bahwa hingga saat ini penggunaan hijauan makanan ternak dari kawasan hutan oleh masyarakat desa Jingkang masih sangat besar. Dalam memperoleh hijauan makanan ternak guna kebutuhan usaha ternak ruminansia mereka, masyarakat dusun Ciburuan dan dusun Cicae masih sangat tergantung dari kawasan hutan. Pekerjaan pengambilan hijauan dilakukan oleh masyarakat dengan frekuensi pengambilan rata-rata 29 kali dalam satu bulan. Pengambilan hijauan makanan ternak dari kawasan hutan dilakukan pada siang hari setelah selesai melakukan kegiatan bertani. Masyarakat mengambil hijauan makanan. ternak menggunakan peralatan yang sederhana yaitu arit dan karung berukuran $50 \mathrm{~kg}$ sebagai wadahnya. Hijauan makanan ternak yang sudah terkumpul dalam wadah karung kemudian diangkut dari hutan menuju tempat tinggal mereka. Pengangkutan hijauan makanan ternak dilakukan dengan cara dipikul dan menggunakan kendaraan sepeda motor. Pengangkutan dengan cara dipikul dilakukan oleh peternak yang mengambil hijauan makanan ternak dalam jumlah sedikit sesuai dgn jumlah hewan ternak yang dimiliki. Sedangkan penggunaan kendaraan sepeda motor dilakukan bagi peternak yang mengambil hijauan makanan ternak dalam jumlah yang cukup banyak sehingga peternak harus mengeluarkan biaya operasional untuk proses pengambilan hijauan makanan ternak tersebut. Besaran biaya operasional bervariasi sesuai banyaknya hijauan makanan ternak yang diangkut atau jumlah ritase pengangkutan.

Jumlah hijauan makanan ternak yang diambil oleh masyarakat dari kawasan hutan sesuai dengan kebutuhan berdasarkan jumlah hewan ternak yang mereka miliki. Semakin banyak hewan ternak yang dimiliki, maka semakin besar jumlah hijauan makanan ternak yang dibutuhkan dan semakin banyak pengambilan yang dilakukan. Hal tersebut sesuai dengan pernyataan Rifqi (2018) yang mengatakan bahwa kebutuhan hijauan akan semakin banyak sesuai dengan bertambahnya jumlah populasi ternak yang dimiliki. Selain itu, Farizaldi (2011) juga mengatakan bahwa pertambahan populasi ternak ruminansia menyebabkan peningkatan kebutuhan pakan hijauan.

2. Nilai Ekonomi HMT yang Dimanfaatkan oleh Masyarakat

a. Nilai Ekonomi HMT satu kali pengambilan.

Nilai ekonomi hijauan makanan ternak yang dimanfaatkan oleh 140 responden dalam satu kali pengambilan diperoleh dari hasil perhitungan nilai ekonomi hijauan makanan ternak satu kali pengambilan dikalikan dengan harga 
pasar hijauan makanan ternak Rp. 15.000,-. Berdasarkan hasil perhitungan diperoleh nilai dengan jumlah Rp. 4.432.500,- dan rata - rata Rp. 31.661,- per kepala keluarga.

\section{b. Nilai Ekonomi HMT dalam satu bulan}

Nilai ekonomi total hijauan makanan ternak dalam satu bulan yang dimanfaatkan oleh masyarakat dari kawasan hutan di desa Jingkang adalah sebesar Rp.126.600.000,- dengan nilai rata-rata per kepala keluarga sebesar Rp. 904.285,71,-. Nilai ekonomi hijauan makanan ternak tersebut diperoleh dari penjumlahan nilai ekonomi hijauan makanan ternak yang dimanfaatkan oleh masyarakat dari dua dusun di desa Jingkang, yaitu sebesar Rp. 41.035.000,- oleh masyarakat dusun Ciburuan dan Rp. 85.565.000,- oleh masyarakat dusun Cicae. Keberhasilan usaha ternak ruminansia masyarakat sangat dipengaruhi oleh ketersediaan hijauan makanan ternak di lingkungan tempat tinggal mereka. Ketersediaan hijauan makanan ternak yang tidak seimbang dapat menyebabkan kegagalan dalam usaha ternak ruminansia. Siregar (2003) menyatakan bahwa pakan memiliki peranan penting dalam keberhasilan usaha peternakan, karena 60 $80 \%$ total biaya produksi digunakan untuk biaya pakan. Hal tersebut didukung oleh pernyataan Tomaszewska et al. (1993) dalam Ayu Astuti dkk. (2015) bahwa jumlah konsumsi merupakan faktor utama yang menentukan jumlah nutrien yang didapat oleh ternak dan selanjutnya mempengaruhi pertambahan bobot tubuh.

Berdasarkan penghitungan data hasil penelitian dapat dilihat bahwa ternyata hijauan makanan ternak yang dimanfaatkan oleh masyarakat secara rutin mencapai nilai ekonomi yang cukup tinggi. Hal tersebut dapat memberikan informasi bahwa kawasan hutan terbukti telah memberikan kontribusi yang cukup besar bagi masyarakat selama ini, khususnya dalam meringankan biaya produksi usaha ternak ruminansia mereka. Dengan demikian, sudah selayaknya masyarakat, khususnya masyarakat desa Jingkang menghargai keberadaan hutan dan turut serta menjaga kelestariannya agar hutan dapat terus menerus berfungsi sebagaimana mestinya guna kesejahteraan masyarakat itu sendiri. Sebagaimana yang disampaikan oleh Hidayat (2015) bahwa pemanfaatan hutan saat ini bertujuan untuk pencegahan banjir, pemungutan hasil hutan untuk pembangunan nasional, konservasi, migrasi, pertanian, peternakan dan perkebunan. 


\section{KESIMPULAN}

Jumlah hijauan makanan ternak yang di ambil oleh 140 responden dalam satu bulan dari kawasan hutan adalah sebanyak 8.650 karung ukuran $50 \mathrm{~kg}$ dengan rata - rata 62 karung untuk setiap kepala keluarga dan nilai ekonomi hijauan makanan ternak yang dimanfaatkan oleh masyarakat dalam satu bulan di desa Jingkang yaitu sebesar Rp.126.600.000,- dengan nilai rata-rata per kepala keluarga sebesar Rp. 904.285,71,--

\section{DAFTAR PUSTAKA}

Ayu Astuti, \& Edy, P. (2015). Pengaruh Cara Pemberian Konsentrat Hijauan Terhadap Peran Fisiologis dan Performa Sapi Peranakan Simmental. The Effect of Providing Forage-Concentrate on Physiological Response and Performance of Simmental Cross Beef Cattle. 3(November), 201-207. Retrievedfrom:http://jurnal.fp.unila.ac.id/index.php/JIPT/article/view/1098.

Farizaldi, F. (2011). Produktivitas Hijauan Makanan Ternak Pada Lahan Perkebunan Kelapa Sawit Berbagai Kelompok Umur Di Ptpn 6 Kabupaten Batanghari Propinsi Jambi. Jurnal Ilmu-Ilmu Peternakan, O(0), 68-73. Retrieved from: https://doi.org/10.22437/jiiip.v14i2.866.

Ginting, Albina Br (2012) Kontribusi Usahatani Padi Dan Usaha Sapi Potong Terhadap Pendapatan Keluarga Petani Di Kecamatan Purwodadi Kabupaten Grobogan. Masters thesis, Program Pascasarjana. Retrieved from: http://eprints.undip.ac.id/42347/.

Hanafi N. D. (2008). Teknologi Pengawetan Pakan Ternak. oleh: Nevy Diana Hanafi. 1-19. Retrieved from: http://repository.usu.ac.id/bitstream/handle/123456789/801/nevy\%2013214 3320.pdf? sequence $=1 \&$ is Allowed $=\mathrm{y}$.

Hidayat, H. 2015. Pengelolaan Hutan Lestari: Partisipasi, Kolaborasi, dan Konflik. Yayasan Pustaka Obor Indonesia. Jakarta.

Nahdi, S. M., dan Darsikin (2014). Distribusi dan Kemelimpahan Spesies Tumbuhan Bawah pada Naungan Pinus mercusii, Acacia auriculiformis dan Eucalyptus alba di Hutan Gama Giri Mandiri, Yogyakarta. 16(1), 33-41. Retrieved from: https://natur.ejournal.unri.ac.id/index.php/JN/article/view/2753/2696. 
Prabowo,2010. Budidaya Ternak Kambing. Retrieved from: http://forclime.org/merang/51-STEFINAL.pdf.

Rifqi Dhiemas Aji, 2018. Mengatasi Ternak yang Kelaparan Nutrisi. Tribunnews.com-Jakarta. Retrieved from: https://www.tribunnews.com/tribunners/2018/08/06/mengatasi-ternak-yang kelaparan-nutrisi.

Siregar, S. B. 2003. Penggemukan Sapi. Penebar Swadaya, Jakarta.

Siregar, S.B. 2003. Ransum Ternak Ruminansia. Penebar Swadaya. Jakarta.

Sitindaon, S. H. (2013). Inventarisasi Potensi Bahan Pakan Ternak Ruminansia Di Provinsi Riau. Jurnal Peternakan, 10(1), 18-23. Retrieved from : http://ejournal.uin-suska.ac.id/index.php/peternakan/article/view/154/0

Tomaszewska, M.W., J.M. Mastika, A. Djaja Negara, S. Gardiner, dan T.R.Wiradarya. 1993. Produksi Kambing dan Domba di Indonesia. Sebelas Maret University Press. Surabaya

Umi Wisapti Ningsih. (n.d.). Rentabilitas usaha ternak sapi potong di desa wonorejo kecamatan poncokusumo kabupaten malang. 48-53. Retrieved from: https://ternaktropika.ub.ac.id/index.php/tropika/article/view/102/98 